\title{
NUEVOS DATOS BIOGRÁFICOS SOBRE JUAN DE MIRALLES
}

\author{
Vicent RIBES \\ Universitat de Valencia
}

\section{Resumen}

Aportación de nuevos datos biográficos inéditos de Juan Miralles Trayllon, negociante establecido en La Habana en 1740 , elemento importante en el tráfico esclavista y agente de España durante los años de la guerra de Emancipación de los EE. UU. de América.

\begin{abstract}
Contribution of new unpublished biographical data of Juan Miralles Trayllon, a dealer who was established in La Havana in 1740, important element in the slaveholding traffic and agent of Spain during the years of the Emancipation war of the United States of America.
\end{abstract}

Don Juan de Miralles ayudó con todas sus fuerzas y capitales al triunfo de la Revolución de Independencia de los Estados Unidos. Su actividad, sin embargo, se desarrolló dentro de los límites semi-clandestinos impuestos por la voluntad de su rey, Carlos III, y esa es la razón de que la historiografía americana, estudiosa hasta la saciedad de todo lo relacionado con el general Washington y su época, desconozca la aportación de este hombre, y de los españoles en general, a su causa. Quizá habría que añadir también otra razón más incómoda: la desconfianza que todo lo español y católico ha suscitado tradicionalmente en el mundo anglosajón, de lo que encontramos un buen ejemplo en los escritos de Alexander Hamilton, el secretario del general Washington, que escamoteó en sus relaciones la trascendencia de la ayuda española a la causa americana, así como el respeto y amistad que el general profesó a Miralles, temas bien conocidos por Hamilton. Sin embargo, cuando Miralles murió en Morristown en 1780, las tropas americanas honraron la ceremonia de su entierro, y su última enfermedad y muerte transcurrieron en la casa del general, como una muestra más de gratitud del pueblo americano.

Los autores españoles e hispanoamericanos ${ }^{1}$ que se han interesado por el personaje, han centrado sus estudios en los dos últimos años de su vida, aquellos en los que

1. FERNÁNDEZ Y FERNÁNDEZ, E., «Juan de Miralles, pionero de la diplomacia española en los Estados Unidos», Cuadernos de la Escuela Diplomática, ${ }^{\circ}$ 5, Madrid, Diciembre, 1990. MATZKE 
desarrolló su labor diplomática en los Estados Unidos, período que es hoy en día sobradamente conocido. Pero cuando se refieren a los sesenta y cinco años anteriores de su biografía, lo hacen cumplimentando apresuradamente el trámite, e incluso, en algunas ocasiones, haciendo suposiciones gratuitas o simplemente inventando. En este artículo nos proponemos alterar los términos: aportar datos novedosos sobre esos años oscuros de la existencia de Miralles, y resumir brevemente el epílogo de la misma, introduciendo consideraciones inéditas.

Juan de Miralles y Troilón o Trayllon nació en la población alicantina de Petrer a las seis horas del 23 de julio de 1713, siendo bautizado el mismo día en la iglesia de San Bartolomé por el cura Fray Ginés Durá, y siendo sus padrinos Bartolomé Avellán y Beatriz Chico. Los abuelos paternos del neófito eran Santiago de Miralles, de ascendencia hidalga, secretario del rey en la chancillería de Navarra, y señor de la propiedad de Manaud, cercana a la villa de Monein, en el Bearn, y Juana Tísner, natural de esta última población. Los abuelos maternos eran Santiago Trayllon y Juana Desusbieles, de la cercana localidad de Arbus. Y sus padres, el capitán de infantería Juan de Miralles, nacido en Manaud y de servicio en España defendiendo la causa sucesoria de Felipe de Anjou, y Gracia Trayllon, natural de Arbus. La boda de estos dos últimos personajes, progenitores del Juan de Miralles a quien vamos a dedicar las siguientes páginas, tuvo lugar en Petrer, por lo que es de suponer una cierta permanencia en su destino del mencionado militar -Petrer fue partidario del pretendiente borbónico durante la Guerra de Sucesión española y en sus inmediaciones se mantuvieron enconados combates contra las tropas partidarias del archiduque Carlos de Austria-. ${ }^{2}$ Por lo demás, nada tiene de extraordinaria la procedencia bearnesa de la familia, pues bearnés y emigrante llegaron a ser sinónimos durante la denominada Edad Moderna, y de esa región procedían la mayor parte de franceses asentados en el Reino de Valencia durante el siglo XVIII. ${ }^{3}$

Pues bien, Juan de Miralles fue el segundo hijo del matrimonio del militar homónimo y de Gracia Trayllon, quienes residieron «en el reino de España» hasta 1728. Aunque mantenemos serias dudas sobre la permanencia de la familia en Petrer durante esos primeros quince años de vida de Juan de Miralles, lo bien cierto es que los Miralles eran bien conocidos entre la colonia de comerciantes galos asentada en el

MC-CADDEN, Helen, «Juan de Miralles and the American Revolution, The Americas, 1973, vol. XXIX, $n^{\circ}$ 3. PRADELLS NADAL, Jesús, Diplomacia y comercio, Alicante, 1992. PORTELL VILA, Herminio, Juan de Miralles, un habanero amigo de Jorge Washington, La Habana, 1947 y Los «otros extranjeros» en La Revolución Norteamericana, Miami, 1978.

2. Declaraciones de Juan Francisco Miralles y Eligio de la Puente, Trayllon y González, oficial de la contaduría principal del ejército de La Habana, para ser nombrado caballero supernumerario de la Orden de Carlos III. Habana, 23 de abril de 1792. Archivo Histórico Nacional, Estado, Carlos III, exp. 870. En ellas nos basaremos repetidamente a lo largo del presente estudio cuando no citemos otro tipo de fuente.

3. Ver al respecto los estudios de DESPLAT, Christian, Pau et le Bearn au XVIlle siecle, 2 vols, Biarritz, 1992. POINTRINEAU, A., «La inmigración francesa en el Reino de Valencia (Siglos XVI-XIX)», Moneda y crédito, $\mathrm{n}^{\circ} 137$, julio 1976, pp. 103-133, y de ALONSO PÉREZ, Matilde, «Un estudio de aplicación de las técnicas informáticas a la investigación histórica. El comercio mediterráneo franco-español a fines del s. XVIII», Revista de Historia Moderna, Universidad de Alicante, ${ }^{\circ}$ 3, 1983, pp. 115-137. Para conocer la composición de la colonia francesa en Alicante, GIMÉNEZ LÓPEZ, Enrique, Alicante en el siglo XVIII, Valencia, 1981. Y para otras comarcas valencianas, RIBES, Vicent, Secrets del Castelló set-centista, Valencia, 1987, y FRANCH BENAVENT, Ricardo, El capital comercial valenciano en el sigk XVIII, Valencia, 1989. 
puerto de Alicante, con quienes mantuvieron siempre contactos esporádicos. Como muchos otros franceses, el militar quizá orientase su nueva vida hacia el comercio, pero lo bien cierto es que su nombre no aparece entre la nómina de comerciantes de la ciudad de Alicante, ni tampoco entre los asentados o «matriculados» en el emporio gaditano ${ }^{4}$. Sea como fuere, el año 1728 , el capitán Miralles se vió obligado a trasladarse a su casa solariega de Manaud para hacerse cargo de la heredad por muerte de su padre, y con él parte de sus familiares, entre los que se encontraba su hijo Juan. La mansión y las depedencias anexas de Manaud debieron ser restauradas por el nuevo propietario, pues en la clave del arco que da acceso a la granja todavía se puede leer el año «1731». La estancia del joven Miralles en las tierras de sus antepasados, sin embargo, apenas duró tres o cuatro años, pues en 1732 volvió de nuevo a España, contando diecinueve años de edad, para no regresar jamás al Bearn.

El misterio rodea de nuevo los siguientes ocho años de su vida, y sus actividades nos son desconocidas hasta que, el año 1740, desembarca en La Habana, con veintisiete años y un capital extraordinario, 8.500 pesos, lo que le permitirá optar con éxito a la mano de la hija de una de las familias más acaudaladas de la isla de Cuba. Semejante fortuna es, con mucha diferencia, mayor que cualquier otra de las casas de comercio establecidas en la ciudad de Alicante, ciudad donde no hubiese pasado desapercibida. Sin embargo, como hemos dicho, Miralles no aparece ejerciendo ninguna actividad mercantil de importancia en dicha ciudad, ni tampoco en Cádiz. La explotación agrícola bearnesa de su padre apenas bastaría para mantener la familia de su progenitor con algún decoro, por lo que no se puede pensar en ella como el origen de tanto dinero. Por tanto, y a la vista de las actividades mercantiles que Miralles desempeñaría con posterioridad, bien podemos concluir que durante esos años oscuros cimentó su dedicación al tráfico de esclavos, lo que explicaría tanto el oscurantismo de sus ocupaciones como el origen de su fortuna.

Pero retomemos el hilo de los acontecimientos. Hemos dicho que el año 1740 llegó Juan de Miralles a La Habana. Cuatro años después, el 22 de agosto de 1744, se casó en la iglesia del Espíritu Santo con doña María Josefa Eligio de la Puente y González-Cabello, natural de dicha ciudad, hija de Julián y Bárbara, ambos habaneros, y nieta del capitán de infantería sevillano José Eligio de la Puente, que casó en La Habana el 4 de abril de 1688 con doña Francisca de Ayala, hija a su vez de don Juan Francisco Buenaventura de Ayala y Escobar, Capitán de Mar y Guerra, General de Galeones, Sargento Mayor, Capitán General y Gobernador de San Agustín de la Florida. ${ }^{5}$ El interés de tan largo árbol genealógico reside en comprobar que la familia de la esposa de Miralles estaba firmemente asentada tanto en la isla de Cuba como en la Florida, península en la que vivían muchos de sus familiares y hacia donde se encaminarían de inmediato algunos de los negocios del valenciano. Miralles, ya lo hemos dicho, aportó al matrimonio 8.500 pesos. Josefa, nada, aunque al cabo de poco tiempo heredó 1.600 pesos correspondientes al quinto de la herencia de su abuela Leonor Sánchez Cabello, a los que sumó otros 600 pesos heredados tras el fallecimiento de su tío Francisco Eligio de la Puente. El joven matrimonio se instaló en una casa de la

4. GIMÉNEZ LÓPEZ, E., 1981, y RIBES, Vicent, Comerciantes, esclavos y capital sin patria, Valencia, 1993, para el caso alicantino. Para Cádiz, RUIZ RIVERA, Julián B., El Consulado de Cádiz, matrícula de comerciantes. 1730-1823. Cádiz, 1988.

5. SANTA CRUZ Y MALLÉN, F. X. de, Historia de familias cubanas, t. 5, La Habana, 1944. 
calle de Aguiar, cercana al puerto de La Habana, con almacenes y dependencias anexas, ${ }^{6}$ y tuvo ocho hijos, un varón y siete hembras. El año 1745 nació su hija Antonia Josefa, en 1748 María Bárbara, en 1749 María Guadalupe, en 1751 Josefa Loreto, en 1752 Ana Josefa, en 1753 María Jesús de la Trinidad, en 1758 María Francisca de los Dolores, y el 27 de octubre de 1759 Juan Francisco, el único varón, siendo su padrino de bautizo el capitán de navío Juan Benito Erasun.

Desde La Habana, principio y fin, compendio y recapitulación de toda aventura y negocio americano, Miralles comenzó a comerciar con la Florida y, por extensión y pese a que en algunos períodos se rozaba la ilegalidad, con los puertos ingleses de Charleston, Philadelphia, New York y Boston. Sus negocios debían ser de índole muy variada, desde la compra y venta de buques al transporte y contrabando marítimo. Sin embargo, su principal objeto de atención era, sin duda alguna, el tráfico de esclavos, en el que participó tanto por su cuenta y riesgo como formando sociedad con otros comerciantes. Estas actividades las ejerció de forma paralela a la de agente secreto o comisionado real. En una de las últimas cartas que Miralles escribió en su vida afirmaba, a propósito del insoportable calor que reina en la isla de Jamaica a partir del mes de abril, que «Yo he estado en dicha isla más de nueve meses con comisión pública del Real Servicio y tengo vastante experiencia de que es aquel clima». También sabemos que el 9 de mayo de 1762, Miralles informaba a la corte desde la isla de San Eustaquio, de los preparativos bélicos que hacían los ingleses. ${ }^{8}$ Estos datos no tienen desperdicio, puesto que confirman que antes de que fuese nombrado embajador extraoficial de España ante el Congreso de los Estados Unidos, Miralles ya había sido comisionado por el rey en otras épocas anteriores como agente o informador secreto de los movimientos ingleses. Pero, además, indica que conocía bien Jamaica, la principal proveedora de esclavos para las colonias españolas, y todo el Caribe.

Miralles fue la pieza clave en el comercio negrero hispánico durante los años sesenta y setenta del siglo XVIII, y su nombre aparece asociado al de cualquier empresa negrera de mayor o menor envergadura, actuando por sí mismo o a través de prestanombres de la ciudad de Alicante, comerciantes leales y viejos conocidos suyos. La conexión alicantina de Miralles queda fuera de toda duda, aunque en algunos casos sea muy difícil de probar. Seguramente Miralles estaba ya relacionado con el asiento de negros concertado en 1761 entre el alicantino José Villanueva Picó y la Real Hacienda ${ }^{9}$. Picó era un veterano y experimentado asentista que se hallaba matriculado en el Consulado de Cádiz en fecha tan temprana como 1734. La instancia de Picó y Compañía para obtener el asiento proponía transportar de La Habana a la península Ibérica tabaco, cañones, balas y otros pertrechos bélicos que la Real Hacienda considerase oportuno, a cambio de la libre introducción de esclavos en Cuba por espacio de diez años. El tráfico debía realizarse en naves bien tripuladas y dotadas de un mínimo de veinticuatro cañones. García Baquero supone ${ }^{10}$ que al no aparecer entre los

6. WEISS, Joaquín E., La arquitectura colonial cubana. La Habana-Sevilla, 1996.

7. Miralles a Gálvez, Philadelphia, 7 de abril de 1780, Archivo Histórico Nacional (A.H.N.), Estado, leg. 3884 bis. Exp. 6, n 10 y 11 .

8. Archivo General de Indias (A.G.I.), Santo Domingo, leg. 944.

9. A.G.I., Contratación, leg. 5083.

10. GARCÍA BAQUERO GONZÁLEZ, Antonio, Cádiz y el Atlántico. (1717-1778), Sevilla, 1976, p. 353. 
navíos consignados como negreros ninguno cuyo propietario fuese Picó, el asiento no se realizó nunca, máxime si tenemos en cuenta que en 1762 Cuba sería invadida por los ingleses y se interrumpirían totalmente las relaciones comerciales con la metrópoli.

Sin embargo, el año 1764 se hizo en La Habana una nueva contrata para introducir mil negros, siendo el asentista el mismo Villanueva Picó, quien se comprometió a dar a las arcas reales 2.000 pesos y a vender cada cabeza a la Real Hacienda a 158 pesos. Ese mismo año la Real Hacienda compró también a Cornelio Coppinger, a la Compañía de La Habana y a José Uqué, 972 negros a precios que oscilaron entre 130 y 156 pesos. ${ }^{11}$ Cornelio Coppinger O'Brian, natural de la ciudad de Cork, Irlanda, y propietario de una casa de comercio en Alicante junto a su socio Miguel Kearney, ${ }^{12}$ quien a su vez formaba otra compañía con los comerciantes alicantinos de origen francés Bouligny, pasó a residir a La Habana el año 1763, obteniendo carta de naturaleza española por Real cédula de 23 de marzo de 1767 y dedicándose al comercio de esclavos a la sombra de Miralles. ${ }^{13}$ Había casado en Madrid con la habanera María de los Dolores López de Gamarra, familiar de la esposa de Miralles.

El año 1766, al año justo de la fundación de la Compañía Gaditana de Negros, la empresa negrera más grande jamás creada en el imperio español, Miralles entró a formar parte de la misma como accionista, tenedor de 70 acciones de las 960 de la Compañía. Junto a sus ocho socios, Juan Miralles fue el encargado de decidir el destino de las actividades de la Compañía desde La Habana. Se le asignó un sueldo de 2.500 pesos anuales, y es de suponer que fue escogido como socio a causa de sus relaciones y sus conocimientos sobre el mercado de esclavos, puesto que no aportó ningún capital a la sociedad. El 26 de septiembre del año 1772 la Compañía entró en una profunda crisis, y Miralles quedó alcanzado con una deuda astronómica, 70.000 pesos, que haría que fuese excluido definitivamente de la lista de socios en la remodelación que se efectuó para reflotar la economía de la corporación. ${ }^{14}$

Cuando el año 1776 la administración estatal intentó liberalizar el tráfico de esclavos dando entrada a nuevos asentistas, se presentaron varios proyectos para sustituir el monopolio de introducción de esclavos en el imperio español, hasta entonces ejercido por la Compañía de Aguirre Aristegui, uno de los antiguos socios de Miralles. Uno de ellos iba firmado por Juan de Miralles, el antiguo miembro de la Compañía, que ahora se comprometía a proveer de negros la isla de Cuba al ventajoso precio de 225 pesos cada esclavo, 65 pesos más barato que los proporcionados por la Compañía de Aristegui. De la magnitud del comercio que se proponía llevar a cabo y de la seguridad que tenía en el éxito de su empresa da razón el hecho de que se comprome-

11. TORRES RAMÍREZ, Bibiano, La Compañía Gaditana de Negros. Sevilla, 1973, p. 114

12. La sociedad mercantil de Kearney y Coppinger quedó disuelta en abril o mayo de 1777 porque, a juicio de José Bouligny, «no era favorable para Kearney». Miralles se relacionaba, además, con el comerciante alicantino de origen francés Pedro Montengón, padre del jesuíta ilustrado del mismo nombre. José Bouligny a su hermano Francisco. Alicante, 24 de mayo de 1777 . Historic New Orleans Collection (H.N.O.C.), Dauberville-Bouligny Papers (D.B.P.), f. 9.

13. SANTA CRUZ Y MALLÉN, Francisco Javier, Historia de familias cubanas. Habana, 1940, t. VII, p. 109.

14. A.G.1., Indiferente general, leg. 2820 y TORRES RAMÍREZ, pp. $49-50$ y 80 a 95. 
tiese por escrito con la Hacienda estatal al pago de 200.000 pesos anuales durante los diez años estipulados en el asiento, cantidad que representaba la diferencia del precio entre sus esclavos y los vendidos por su oponente en la licitación. Miralles pensaba vender en Cuba, por tanto, un mínimo de 3.000 esclavos al año. ${ }^{15}$ Muy posiblemente, entre los socios de Miralles se contasen los comerciantes alicantinos Bouligny, junto con su socio Miguel Kearney, que también solicitaron el mismo año 1776 la obtención de un asiento del estado con el objeto de transportar cien esclavos desde Africa a Nueva Orleans, vía Cuba. ${ }^{16}$ Por lo que respecta a la solicitud de Juan de Miralles, el Consejo de Indias la desestimó por considerar al alicantino «hombre de mas tramoya y apariencia que solidez y sustancia» ${ }^{17}$, y la de los Bouligny parece que ni siquiera fue tomada en consideración..$^{18}$

Al llegar a este punto, y antes de proseguir con el hilo de los acontecimientos, hemos de efectuar una serie de reflexiones y trazar un paralelismo biográfico harto ilustrativo. Cuando llega el año 1776, la fortuna y el crédito de Miralles están ya a salvo de cualquier contingencia. Era un hombre de probada capacidad empresarial que, además, había sido reconocido por el propio soberano a cuyo servicio directo, recordémoslo, había pasado, como mínimo, casi un año en Jamaica. En dicho contexto, el dictamen del Consejo de Indias sólo podía servir para ocultar o desviar la atención de la empresa que el rey acababa de encomendar a Miralles y Bouligny. Repasando la biografía de Don Francisco Bouligny encontraremos la confirmación de dicha hipótesis.

En la ciudad de Nueva Orleans, en el atrio de la catedral de San Luis y en lugar destacado, reposan los despojos de otro de los valencianos más universales del siglo XVIII, Francisco Bouligny, gobernador interino de Luisiana, prominente hacendado en las orillas del Mississippi y ensayista notable. Muchas son las razones que hacen de Francisco Bouligny y de sus hermanos José y Juan unos personajes descollantes. En primer lugar porque su familia regentó la mayor casa de comercio de la ciudad de Alicante hacia mediados del siglo XVIII. En segundo lugar, porque la educación cosmopolita y económica de los tres hermanos les permitió escribir una serie de obras muy valiosas, tanto desde el punto de vista teórico como por el hecho de que, en la práctica, inspiraron más o menos directamente muchas medidas de Estado: creación del Consulado de Comercio de Alicante, de los primeros billetes - los famosos «vales reales»-, fundación del Banco de San Carlos, fomento comercial de Luisiana, etc. En tercer lugar por la misma importancia de los cargos que, sobre todo Francisco y Juan, desempeñaron: gobernador de Luisiana y primer embajador español en Turquía, respectivamente. Y por último, pero no menos importante, porque tan deslumbrantes trayectorias vitales inspiraron las obras literarias de otro alicantino, Pedro de Montengón, consideradas como el punto de partida de la moderna novela española. Pero de-

15. Súplica de Juan Miralles. La Habana, 12 de octubre de 1776. A.G.I., Santo Domingo, 2516.

16. José y Juan Bouligny a su hermano Francisco. 3 de Septiembre de 1776. H.N.O.C., Bouligny-Baldwin Papers (B.B.P.), f. 45.

17. A.G.I., Santo Domingo, 2533.

18. José Bouligny a su hermano Francisco. Alicante, 10 de Septiembre y 2 de octubre de 1776. H.N.O.C., D.B.P., f. 8 y B.B.P., f. 46. 
jemos al margen tan brillantes biografías, y centrémonos en un período muy concreto de la vida del militar Francisco Bouligny. ${ }^{19}$

El 21 de julio de 1762 salió Francisco Bouligny de Cádiz, junto con su regimiento, el Fijo de La Habana, para efectuar un largo periplo que le conduciría como meta final, siete años después, a tierras de Luisiana. Primero estuvo un año en Tenerife esperando el fin de la guerra anglo-española por el dominio de La Habana. Después, seis años de guarnición en esta última ciudad, y cuando se preparaba para solicitar un nuevo destino en la Península Ibérica, el 6 de julio de 1769, recibió órdenes para integrarse en el cuerpo expedicionario que iba destinado a Nueva Orleans. A pesar de ser un simple teniente por aquel tiempo, su dominio del francés le prestó un ascendiente como traductor e intermediario entre los expedicionarios españoles y la población francófona desproporcionado para el grado militar que ostentaba. En noviembre del mismo año sería nombrado capitán y, en diciembre de 1770 , se casaría con Marie Louise Le Sénéchal D'Auberville, descendiente de una de las familias más prominentes de Nueva Orleans. El destino del militar alicantino quedaría por siempre ligado a la ciudad de su esposa, tanto en el aspecto familiar como en el profesional, pues las propiedades y la influencia que su matrimonio le proporcionaron entre la población autóctona le sirivieron de base para acelerar su carrera militar, bastante lenta y desafortunada hasta entonces. Pero antes de establecerse definitivamente en América, Francisco Bouligny efectuó un último, largo y misterioso viaje a Madrid el año 1776.

De que Miralles y el padre y hermanos mayores de Francisco Bouligny se conocían bien, no existe la menor duda. El primero aparece mencionado en la correspondencia de Bouligny con sus hermanos y, además, hemos visto que compartían socios y conocidos entre la docena de descendientes de franceses que se dedicaban al comercio en Alicante. No es nada aventurado afirmar que, pese a la diferencia de edad -veintiún años-, los seis años que Bouligny pasó en La Habana -una ciudad de cincuenta mil habitantes en aquella época-, darían a ambos hombres sobradas oportunidades de conocerse mejor.

Lo cierto es que el año 1772 Francisco Bouligny solicitó un permiso a sus superiores para trasladarse a la Península Ibérica por un tiempo indefinido. Pasaron los años, y no fue sino en la primavera de 1775 cuando dicho viaje se hizo efectivo. El detalle llama la atención, pues nadie solicita un permiso para hacerlo efectivo tres años después. Pero, además, una vez en España, lejos de su familia y su tierra de adopción, Bouligny pasó más de un año en ella sin que nos expliquemos a ciencia cierta cual haya sido el motivo de su viaje ni el de tan dilatada estancia. Para visitar a sus hermanos en Alicante y darles un último adiós no fue. Para arreglar asuntos económicos de la familia de su esposa tampoco y, además, por entonces residía en Madrid un cuñado suyo que, llegado el caso y con un simple otorgamiento de poderes, hubiese podido ahorrarle el viaje. A mayor abundamiento, Bouligny se puso a redactar una magnífica Memoria histórica y política sobre Luisiana, a miles de millas de distancia de dicha tierra, en Madrid, sin la ayuda de libros, personajes o comproba-

19. DIN, G. C., BOULIGNY, F., A Bourbon soldier in Spanish Louisiana, Baton Rouge, 1993. FONTAI$\mathrm{NE}$, Martin, A History of the Bouligny family and allied fanilies, Lafayette, 1990. RIBES, Vicent, 1993. 
ciones directas -de hecho la obra se resiente de algunas inexactitudes-, lo que le ocupó algunos meses. Resulta a todas luces evidente que nadie se va al otro lado del mundo y se separa de sus familiares para redactar una obra que hubiese podido terminar con mucho mayor rigor científico en la tierra objeto de atención.

Nuestra visión del viaje de Bouligny a la corte de Madrid debe de estar relacionada con el acuerdo reservado del ministro Floridablanca, sin fecha y autografiado ${ }^{20}$, en el que expresa la conveniencia de que se encargase a las autoridades de La Habana o de la Luisiana, a entera confianza del secretario del Despacho de Indias, el comisionar una o dos personas que se internaran en las colonias inglesas insurgentes y se instruyesen y comunicasen con las debidas precauciones las novedades de importancia. Debían instalarse en el paraje en el que se hiciera la guerra principal, estableciendose cerca de alguno de los generales en jefe, realista o insurgente, y en el lugar en que se hallasen los diputados del Congreso. Debían informar sobre la marcha y progresos de la guerra, los propósitos de ambos bandos, sobre todo si se relacionaban con España o sus Indias, y convencer a los protagonistas de que nada se debía hacer sin el acuerdo de Francia y España. A estos fines añadía Floridablanca que a los agentes «se les facilitarían todos los auxilios que necesitaran y el dinero y crédito que hubieren menester, sin reparar en perjudiciales economías».

Pues bien, aunque desconozcamos la fecha exacta en que fue llamado a consultas para ser designado agente del rey de España para esta finalidad concreta, bien puede suponerse que los primeros contactos de la corte con Juan de Miralles tuvieron lugar entre las primeras manifestaciones de descontento motivadas por la promulgación de la Stamp Act de marzo de 1765, o las de la Townshend Revenue Acts de junio de 1767 y las modificaciones de la Tea Act de 1773. Y no es descabellado pensar que Miralles diese de inmediato el nombre de Bouligny como persona de confianza, en quien coincidían las prendas de ser uno de los mejores conocedores del Valle del Mississippi y su perfecto enraizamiento en la región. Cuando los años 1774 y 1775 confirmaron la consistencia del movimiento rebelde, la corte madrileña decidió que había llegado el momento de llamar a Madrid a sus agentes, Miralles y Bouligny. El 12 de mayo de 1775, el capitán Francisco Bouligny partía de Nueva Orleans rumbo a Madrid, ciudad en la que residiría hasta finales de diciembre de $1776 .{ }^{21}$

Otros tres agentes españoles ${ }^{22}$, también familiares y conocidos de Miralles, serían enviados a otros puntos clave del mar Caribe. Juan José Eligio de la Puente y Re-

20. A.H.N. Estado, leg. 3.885 , exp. 17, $\mathrm{n}^{\circ} 1$.

21. Miralles comunicaría a la familia de Bouligny su feliz arribo a La Habana el 14 de marzo y su partida hacia Nueva Orleans dos días después. José Bouligny a su hermano Francisco. Alicante, 24 de marzo de 1777. H.N.O.C., D.B.P., f. 9.

22. Raffelin nació en París el año 1730. Primero sirvió en los regimientos militares españoles de Italia, y desde 1762 en los de América, participando en el sitio de La Habana. Fue capturado por los ingleses y arrestado en la isla de Jamaica. Tras su liberación, y «por gracia real de su persona», fue nombrado coronel del regimiento de Dragones de América, de guarnición en La Habana y, con posterioridad, de los Dragones Provinciales de Puebla, en México. En 1788, Raffelin era considerado por sus superiores «un hombre difícil a causa de su extraño carácter». Archivo General de Simancas, Secretaría de Guerra, 7259, exp. 3. Eligio de la Puente escribió sobre los indios Uchiz y Talapuches de Florida, sobre los que tenía gran ascendiente, y sobre la historia de la Florida en la época española. A.H.N., Estado, leg. 3884 , $\exp .1, n .7$, y exp. 3, n. 129 respectivamente. 
gidor, primo hermano de la esposa de Miralles, fue comisionado a la Florida inglesa para vigilar los movimientos británicos e indagar las posibilidades de obtener ayuda de los indios de la región ante un eventual ataque español. A Haití pasó el coronel de origen francés Antonio Raffelin, destinado en el regimiento de los Dragones de América, de guarnición en La Habana. Y, por último, a Jamaica marchó un comerciante habanero muy conocido de Miralles, Luciano de Herrera. Por lo tanto, los servicios secretos españoles desplegados en el arco caribeño -Nueva Orleans, Cuba, Jamaica, Haití y San Agustín de la Florida- formarían la trama puesta al servicio de Miralles, que ocuparía la pieza clave del mismo: Philadelphia. Era una especie de reconocimiento del favor real para un agente que ya para entonces, y según su propia confesión fechada el 12 de octubre de 1776, había «expuesto muchas vezes su vida, expendido su caudal, y hecho otros importantes servicios» a su soberano. ${ }^{2.3}$

A los sesenta y cuatro años, el 31 de diciembre de 1777, en la goleta Nuestra Señora del Carmen, partió Miralles de La Habana para dirigirse a Charleston, no sin antes realizar testamento en la primera ciudad mencionada, en el que firmaron como testigos Ignacio Ponce de León, Francisco Rendón, José María de Piña, Juan Antonio Varón y Santiago García Pomarin. Por cierto, en él queda asentado que su hijo Juan Francisco se hallaba en esas fechas «ausente en los reinos de Francia», sin duda en las tierras patrimoniales de sus antepasados. En Charleston permaneció hasta la primavera, donde fue acogido por el gobernador de Carolina del Sur, Edward Rutledge, y compró otra goleta, bautizada San Andrés, para que sirviese de medio de comunicación con el capitán general de Cuba y, al mismo tiempo, se dedicase al comercio entre La Habana y las colonias inglesas sublevadas. A finales de mayo llegó a la ciudad de Philadelphia, recién liberada, no sin antes pasar por Carolina del Norte, donde se entrevistó con su gobernador Abner Nash, y Virginia, donde rindió visita al gobernador Patrick Henry. El comisionado español se instaló en Philadelphia ${ }^{24}$, por lo tanto, un mes antes de la llegada del primer embajador francés en los Estados Unidos, Conrad Alexander Gèrard, con quien, al igual que con su sucesor, el Chevalier de La Luzerne, le uniría una buena amistad.

Dotado de un carácter abierto, y una personalidad brillante y cosmopolita, Miralles atrajo de inmediato la atención de la sociedad de Philadelphia. Desarrolló una entrañable amistad con el financiero Robert Morris, a quien muy probablemente conocía desde hacía tiempo y con quien incluso llegó a tener intereses comerciales comunes. Las goletas de Miralles y Morris se turnaron en los primeros viajes de comercio directo entre Philadelphia y La Habana. Sus embarcaciones -las goletas llamadas «Doña María Bárbara», en evidente referencia a la segunda hija de Miralles, «Buck Skin», «D. Miralleson», «San Antonio», «Marte», «San Andrés» y «El Galgo»transportaban los más variados productos -arroz, azúcar...- y los pliegos conteniendo los informes de Miralles. A los espléndidos banquetes que Miralles ofreció en su residencia asistieron repetidamente el general Washington y su esposa, el marqués de Lafayette, los generales Nathaniel Greene, Philip Schuyler, Von Steuven, Dekalb, el

23. A.G.I., Santo Domingo, 2516.

24. Third South Street, al lado de la Powel House. 
pintor Charles Wilson Peale, los mencionados embajadores franceses, gran número de congresistas... 25

Aunque tras la muerte de Miralles, su sucesor, Diego Gardoqui informase al marqués de Sonora que Carolina del Sur debía a Miralles 35.000 pesos, y este último le contestase que, caso de cobrar algo, se retuviese dicho dinero, pues «Miralles no tuvo fondos suyos durante la misión que se le confió» ${ }^{26}$, lo bien cierto es que Miralles dedicó gran parte de su propia fortuna a mantener la causa de los insurgentes americanos. El carácter secreto de esta ayuda económica -hay que recordar que España no estaba oficialmente en guerra con Inglaterra- hace que hoy sea imposible calcular las cantidades de dinero enviadas por España y qué parte de esos capitales salían directamente de la fortuna privada de Miralles. El hecho de que estos trasvases de dinero se realizasen a través del conde de Aranda, embajador español en París, ha llevado a muchos historiadores americanos al tremendo error de confundir dicha ayuda con la que los independentistas recibían de Francia. Pero, para darnos una idea de la trascendencia de la ayuda financiera española, bastará recordar que las inestables economías de los Estados de Virginia, North Carolina, Massachussets, New Hampshire, Connetticut, Rhode Island, Pennsilvania... giraban en torno a esos «Spanish milled dollars» con los que mantenían la insurrección contra Inglaterra.

Al mismo tiempo, Miralles, como delegado de la corte de Madrid, encauzó grandes donaciones de ropa de abrigo, pólvora, armas, medicinas, etc. hacia las tropas de Washington, a través de la española ciudad de Nueva Orleans. Don Bernardo de Gálvez, gobernador de Luisiana, y don Francisco Bouligny, controlaban directamente estas donaciones secretas. Algunas, sin embargo, nos son conocidas, y nos permiten afirmar que sin ellas el ejército del general Washington no hubiese podido resistir los difíciles inviernos de los primeros tiempos de la independencia. El mes de marzo de 1778 el Congreso de los Estados Unidos envió al capitán Willing y a Oliver Pollock a Nueva Orleans para que recogiesen una donación española de «9.000 varas de paño azul y diez y ocho mil varas de paño tinto de lana de las fábricas de Alcoi, 1.710 varas de paño blanco de íd., 2.992 varas de estameña blanca...». Traducido a términos actuales, eso significa que absolutamente toda la ropa de abrigo y uniformes del ejército de Washington procedían de España. En la misma donación se incluían «...6 cajas de quinina, 8 cajas de otras medicinas, 108 rollos de telas de lana y estameña, 100 quintales de pólvora en cien barriles, y 300 fusiles con sus bayonetas en 30 cajas...» En otra ocasión, Franklin hacía patente al conde de Aranda su agradecimiento por haberse recibido en Boston doce mil fusiles de ayuda española... Si consideramos que las tropas del general Washington en Morristown apenas llegaban a cinco mil hombres, calibraremos mejor el sentido de la ayuda española.

Pero, por si fuera poco, los españoles, además de dinero y pertrechos, ayudaron a las tropas de Washington de otro modo: manteniendo a los ingleses ocupados defendiendo sus fronteras en el valle del Mississippi y en la Florida, lo que hizo imposible el agrupamiento de las tropas inglesas contra Washington. Don Francisco Bou-

25. Los informes que Miralles enviaba a la Corte de Madrid están en el A.H.N., Estado, leg. 3884 bis, exp. 6, nos. 1-17. Las noticias sobre los viajes de sus embarcaciones en el A.G.I., Santo Domingo, leg. 944 y 1598.

26. A.G.I., Santo Domingo, leg. 1197 
ligny fue el encargado de mantener a raya a los ingleses en el valle del Mississippi, llevando a cabo una política militar y de colonización en dichas tierras. Al mismo tiempo, participó, a las órdenes de Bernardo de Gálvez, en las labores de distracción de las tropas británicas en la Florida, que culminaron con la derrota inglesa de Pensacola el año 1781. Bien puede pues afirmarse que sin la colaboración de hombres como Miralles, Gálvez o Bouligny, la independencia de los Estados Unidos hubiese resultado, al menos, mucho más difícil de conseguir. ${ }^{27}$

Pero, además, parece que se estableció una corriente de gran simpatía entre el general Washington y Miralles. Una relación amistosa más profunda de lo que la estricta etiqueta establecía para con un representante de una potencia aliada. El 19 de abril de 1780 llegó Miralles, junto con el embajador francés, al campamento de Morristown, donde fueron recibidos con todos los honores. Un tiempo inclemente, sin embargo, había mermado las fuerzas de Miralles durante el camino desde Philadelphia, obligándole a guardar cama en la propia mansión Ford, donde Washington se hallaba hospedado. A pesar de contar con los cuidados de los mejores médicos disponibles, y atendido solícitamente por el general y su familia, Miralles falleció de una pulmonía el 28 de abril de 1780 . Hasta que pudisen ser trasladados sus restos a La Habana, Miralles fue enterrado, lujosamente amortajado con excelentes ropas y un derroche de pedrería, en una ceremonia presidida por Washington, y con el ejército estadounidense rindiendole honores por decisión de su general, en el pequeño cementerio presbiteriano de Morristown.

La estimación de Washington por Miralles quedó reflejada en multitud de ocasiones, pero pueden servir de ejemplo estas frases escritas por el general al embajador francés $-\ll . .$. las atenciones y los honores rendidos al Sr. de Miralles... fueron dictados por la sincera estimación que siempre le tuve» $-^{28}$, a su viuda - «Todas las atenciones que me fue posible dedicar a su fallecido esposo fueron dictadas por la amistad que sus dignas cualidades me habían inspirado»- ${ }^{29}, \mathrm{o}$ al mariscal Navarro, capitán general de Cuba $-\ll \mathrm{I}$ the more sincerely sympathize with you in the loss of so estimable friend, as ever since his residence with us, I have been happy in ranking him among the number of mine. It must however be some consolation to his connexions, to know that in this country he has been universally esteemed and will be universally regretted»-.

Las goletas «El Page» $\mathrm{y}$ «Stephens» condujeron a La Habana la noticia del fallecimiento de Miralles y sus despojos, respectivamente, el verano de 1780 , donde quedó enterrado en la cripta de la iglesia del Espíritu Santo ${ }^{30}$. Quedaban sin resolver, no obstante, los préstamos que Miralles había efectuado a los insurgentes americanos, y a tal efecto, su hija mayor, Josefa, pidió permiso a la corte madrileña para desplazarse desde Cuba a los Estados Unidos con el objeto de intentar cobrar las deudas pendien-

27. Sobre las relaciones entre España y los Estados Unidos, ver GÓMEZ DEL CAMPILLO, Miguel, Relaciones diplomáticas entre España y los Estados Unidos, Madrid, 1946 y YELA UTRILLA, Juan F., España ante la independencia de los Estados Unidos, Lérida, 1925. Sobre la vida de Bernardo de Gálvez, el libro de REPARAZ, Carmen de, Yo sólo, Barcelona, 1986.

28. MCCADDEN, 1973, p. 371.

29. The Writings of George Washington from the original manuscripts sources, ed. por FITSPATRICK, John C., Washington, D.C., 1936, vol. XX.

30. A.G.I., Santo Domingo, leg. 944. 
tes. El 18 de junio de 1786 ya se hallaba en Nueva York, donde permaneció algunos meses mientras el depositario de los créditos efectuados por Miralles en Estados Unidos, Robert Morris, le informaba del estado de las cuentas de su difunto padre e intentaba cobrarlas. En concreto se trataba de dos deudas, una de 21.000 pesos y otra de 14.000, que el estado de Carolina del Sur había prometido pagar a su padre «cuando el erario lo permitiese». Morris juzgaba acertadamente que ese momento no llegaría nunca. ${ }^{31}$ La monarquía hispánica, sin embargo, supo hacer justicia a los familiares de quien tan leal y abnegadamente le había servido - «abandonando sus propios intereses y dilatada familia», en palabras del gobernador de Cuba, Diego José Navarro-, y pensionó a su viuda Josefa Eligio de la Puente con 800 pesos anuales, y a su hijo Juan Francisco con el nombramiento de Caballero de la Orden de Carlos III. ${ }^{32}$

31. A.G.I., Santo Domingo, leg. 1197, e Indiferente General, leg. 1632B.

32. A.H.N., Estado, Carlos III, exp. 870. 